\title{
Spontaneous Combustion of Grain Dust
}

\author{
Li Tian, Linjie Gao and Haishun Xu \\ College of Quality and Safety Engineering, China Jiliang University, Hangzhou, 310018, Zhejiang, China
}

\begin{abstract}
Experimental study on spontaneous combustion of grain dust was carried out in a cylindrical combustion chamber with vertical flow. Thermocouples and gas sample analyzer were used to measure the temperature and gas of spontaneous combustion respectively. The influence of ventilation volume, bulk density and percentage of dust of sample on the spontaneous combustion propagation velocity was investigated. The results indicated that the self-propagation spontaneous combustion is more likely to happen at relatively low ventilation volume. At early stage, the characteristic gas of spontaneous combustion are $\mathrm{CO}_{2}$ and $\mathrm{CO}$. Spontaneous combustion velocity is proportional to ventilation volume while in inverse proportion to bulk density. The spontaneous combustion could transform into flaming easily under certain ventilation volume.
\end{abstract}

Keywords-grain dust; spontaneous combustion; bulk density; ventilation volume

\section{INTRODUCTION}

The grain process industry will produce fibrous rice bran, wheat bran fiber and fine dust and this kind of material is loose and could cause spontaneous combustion easily during storage. The self-propagation spontaneous combustion belongs to combustion that depends on exothermic chemical reaction. Compared with flaming, the spontaneous combustion could sustain and is hard to observe, when the external heat and oxygen concentration are lower. Hence, the current technologies could not confirm the location of spontaneous combustion accurately. For the spontaneous combustion, if the airflow direction corresponds to spontaneous combustion propagation that is downwind spontaneous combustion, whereas is upwind spontaneous combustion. It is a typical downwind spontaneous combustion that the spontaneous combustion spread upward and the oxygen is supplied from the bottom. Hot fresh air through the unburned part and make it preheated, which will improve the temperature of reaction zone and the rate of chemical reaction, then accelerate the transition from spontaneous combustion to flaming and trigger fire and dust explosion [1-2].Meanwhile, spontaneous combustion will produce deleterious gas such as $\mathrm{CO}$. Although the research about wood, textile fiber materials spontaneous combustion and transition to flaming have been accomplished by Gummer, Aldushin and Carter [3-5]. But few studies focused on the spontaneous combustion of fibrous corn and dust. Moussa and Sweis have carried out theoretical and experimental researches on grain dust spontaneous combustion without involving the mixture of grain fibrous material and dust [6-9]. In China, the study mainly focused on the coalmine gob spontaneous combustion and the spontaneous combustion of sulfide ores [10-12]. This paper revealed the controlling factors of spontaneous combustion propagation, characteristics gas composition and the effect of flow rate, bulk density and percentage of dust of sample on the spontaneous combustion propagation velocity by a series of experimental researches.

\section{EXPERIMENTAL APPARATUS AND METHOD}

The experimental device is presented in Figure 1 and Figure 2. The 300-millimeter-high cylindrical combustion chamber with a 150-millimeter diameter is made of fireproof material and covered with insulated mineral wool and steel sheath. The adjustable fan is installed at the bottom of the combustion chamber and provides oxygen to the spontaneous combustion. The porous electric heating plate is the ignition source and is placed on the porous ceramic bracket at the bottom of the combustion chamber to make airflow distribute equally. Therefore, the fuel bed could be considered as one-dimensional heat conduction. Adjusting the electric heating plate by silicon controlled rectifier could change the power of ignition source.

Four nickel thermocouples with a 1-millimeter diameter are mounted on the wall of the combustion chamber and used to record the increase history of spontaneous combustion temperature. One thermocouple is installed at 1-centimeter position above heating plate. The others have interval of 6centimeter with each other. When the spontaneous combustion front arrives, thermocouple temperature is 553 degree Kelvin [7]. Gas sample analyzer at the top of combustion chamber can detect $\mathrm{O}_{2}, \mathrm{~N}_{2}, \mathrm{CO}, \mathrm{CO}_{2}, \mathrm{CH}_{4}$ and other gas concentration of spontaneous combustion. The experimental airflow rate ranges from 0 to 0.467 centimeter per second, which is the ratio of airflow and the cross-sectional area of combustion chamber.

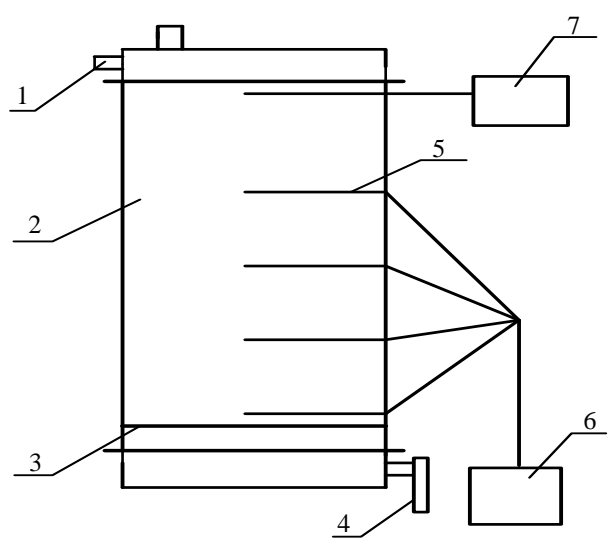

1. Gas vent 2. Combustion chamber 3. Heating plate

4. Fan 5. Thermocouple 6. Temperature recording system

7. Gas sample analyzer

FIGURE I. SCHEME OF EXPERIMENTAL SYSTEM 
The experiments about the impact of external heat source on the spontaneous combustion have been carried out at initial stage and showed that the minimum heat to maintain the spontaneous combustion is 240 watt, which is used in the following experiments.

The wheat bran, less than 5-millimeter in length and the wheat bran dust with 125-micron middle diameter are the parts of spontaneous combustion sample. The three experimental samples with different bulk density and the mass percentage of dust are shown in Table 1.

\section{RESULTS AND DISCUSSION}

\section{A. Characteristic Gas of Spontaneous Combustion}

Table 2 and Table 3 show that in the early stage of spontaneous combustion, fibrous material and dust of grain demand large amounts of oxygen, the oxygen concentration reduces significantly. However, the spontaneous combustion can sustain, which is different from flaming obviously. Consequently, it is difficult to extinguish spontaneous combustion fire by $\mathrm{CO}_{2}, \mathrm{~N}_{2}$ and other inert gas. Small amount of oxygen provided by the production system can support the spontaneous combustion. The mainly characteristic gas are $\mathrm{CO}$ and $\mathrm{CO}_{2}$ that can be used to detect the early spontaneous combustion. Table 2 also indicates that when ventilation rate is certain, the oxygen content increases while $\mathrm{CO}$ and $\mathrm{CO}_{2}$ concentrations decrease as a function of time. This will promote the transition to flaming at the late stage of spontaneous combustion. As can be shown in Table 3, when the ventilation rate is low, the oxygen concentration and the spread speed of early spontaneous combustion decreases. Thus it is an effective method to inhibit the early spontaneous combustion by controlling the air of leakage.

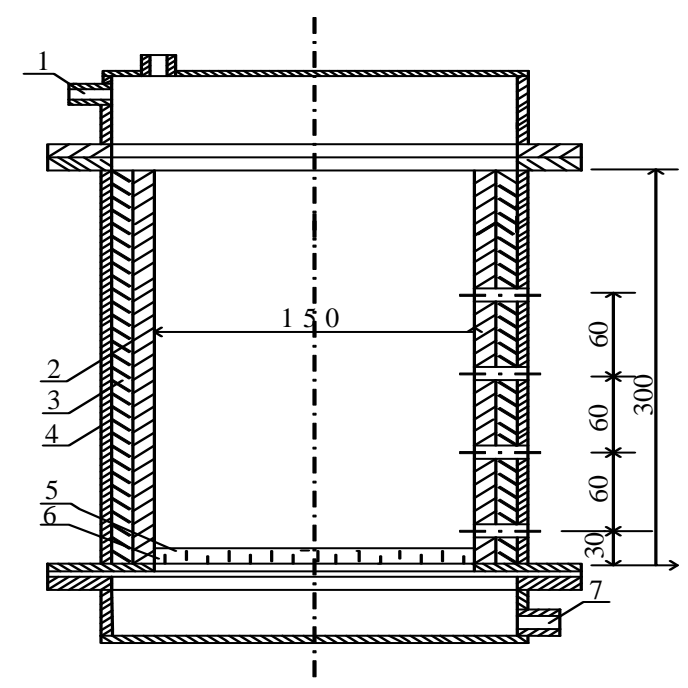

1. Gas outlet 2. Fireproof cylinder 3. Insulation mineral wool

4. Steel sheath 5 . Heating plate 6 . Porous ceramic bracket

7. Gas inlet

FIGURE II. CROSS-SECTIONAL VIEW OF COMBUSTION CHAMBE
TABLE I. BULK DENSITY AND PERCENTAGE OF DUST OF THE SAMPLE

\begin{tabular}{|c|c|c|}
\hline NO & Bulk density $(\mathbf{k g} / \mathbf{m} \mathbf{3}) \mathbf{\pm 1 0} \%$ & $\begin{array}{c}\text { Mass percentage of } \\
\text { dust } \%\end{array}$ \\
\hline 1 & 73.1 & 42 \\
\hline 2 & 99.2 & 69 \\
\hline 3 & 182.7 & 91 \\
\hline
\end{tabular}

B. Influence of Ventilation Volume (Airflow Rate) on Spontaneous Combustion Velocity

For the three kinds of samples, downwind spontaneous combustion propagation velocity with airflow rate is shown in Figure 3. The spontaneous combustion propagation velocity is proportional to ventilation volume. The influence of airflow rate on spontaneous combustion propagation velocity is mainly reflected in the amount of oxygen. Under the low airflow rate and oxygen content condition, spontaneous combustion can be maintained with low speed. With the increase of airflow rate, a plenty of oxygen and heat transfer to unburned zone will promote the speed of reaction.

\section{Effect of Bulk Density on Spontaneous Combustion Propagation Velocity}

When the airflow rate is 0.3-centimeter per second and 0.467 -centimeter per second, spontaneous combustion rate is in inverse proportion to bulk density (Figure 4). The effect of bulk density on the spontaneous combustion propagation velocity is reflected in the sample porosity. The small bulk density of sample has high porosity, which is more favorable for the diffusion of oxygen. Although spontaneous combustion could maintain when the oxygen concentration is low, but its velocity increases with the increase of oxygen concentration. Controlling the proportion of fibrous material and dust in grain sample could change bulk density. When the bulk density is lower, the fibrous material content of sample is higher. Compared with the small size of grain dust, fibrous material is more likely to self-combust under the same condition.

TABLE II. COMPOSITION OF SPONTANEOUS COMBUSTION PRODUCTS FOR SAMPLE 2 AT DIFFERENT TIME AFTER IGNITION; AIRFLOW RATE:0.467 CM/S

\begin{tabular}{|c|c|c|c|c|c|}
\hline Time(min) & $\mathbf{O}_{\mathbf{2}} \%$ & $\mathbf{N}_{\mathbf{2}} \%$ & $\mathbf{C O} \%$ & $\mathbf{C O}_{\mathbf{2}} \%$ & $\mathbf{C H}_{\mathbf{4}} \%$ \\
\hline 30 & 5.95 & 70.71 & 3.73 & 15.90 & 0.41 \\
\hline 120 & 10.94 & 74.03 & 1.38 & 9.00 & 0.12 \\
\hline
\end{tabular}

TABLE III. COMPOSITION OF SPONTANEOUS COMBUSTION PRODUCTS FOR SAMPLE 2 AT 30 MIN AFTER IGNITION WITH DIFFERENT AIRFLOW RATE

\begin{tabular}{|c|c|c|c|c|c|}
\hline $\begin{array}{c}\text { Airflow } \\
\text { rate(cm/s) }\end{array}$ & $\mathbf{O}_{\mathbf{2}} \%$ & $\mathbf{N}_{\mathbf{2}} \%$ & $\mathbf{C O} \%$ & $\mathbf{C O}_{\mathbf{2}} \%$ & $\mathbf{C H}_{\mathbf{4}} \%$ \\
\hline 0.233 & 2.26 & 70.09 & 3.04 & 19.02 & 0.16 \\
\hline 0.467 & 5.95 & 70.71 & 3.73 & 15.90 & 0.41 \\
\hline
\end{tabular}




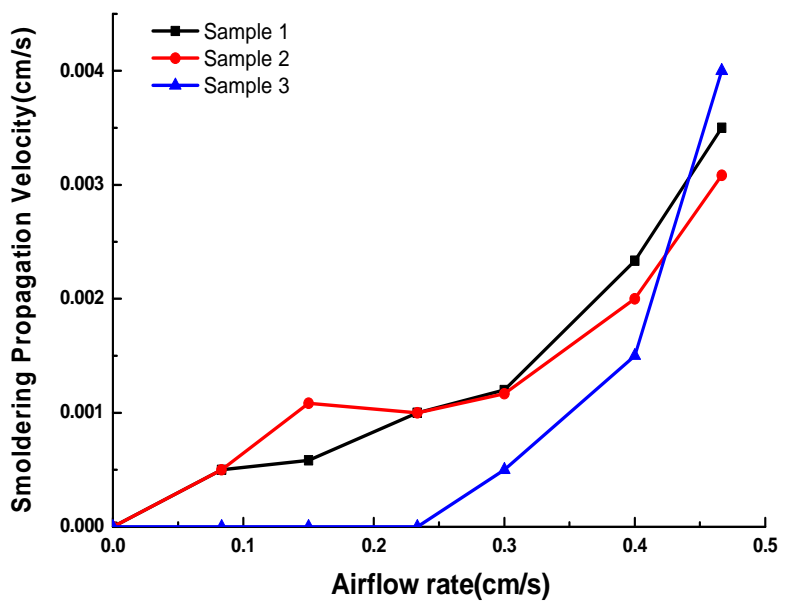

FIGURE III. INFLUENCE OF FLOW RATE ON SPONTANEOUS COMBUSTION VELOCITY

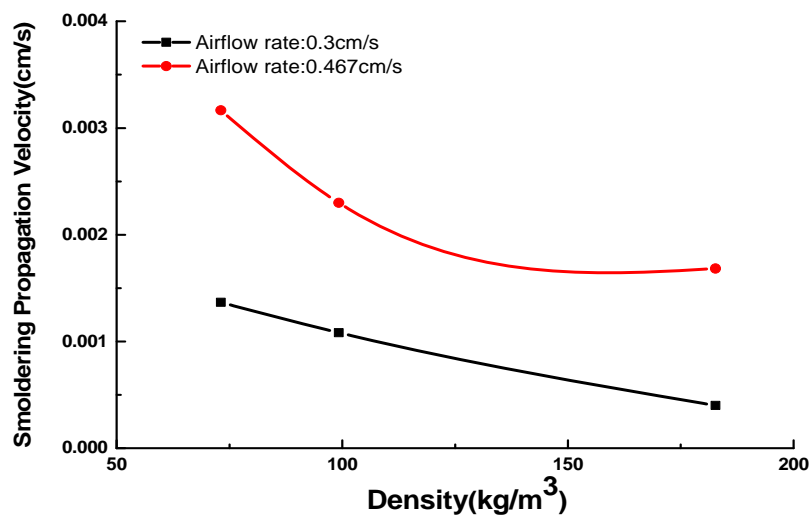

FIGURE IV. INFLUENCE OF BULK DENSITY ON SPONTANEOUS COMBUSTION VELOCITY

\section{CONCLUSION}

1) Even in weak ventilation conditions, the selfpropagation spontaneous combustion of fibrous material and dust of grain could happen. At early stage, the characteristic gas of spontaneous combustion are $\mathrm{CO}$ and $\mathrm{CO}_{2}$. The spontaneous combustion speed is proportional to ventilation volume. Without the external oxygen, spontaneous combustion will be extinguished. When the ventilation rate increase to a certain value, the spontaneous combustion propagation velocity increases and the risk of spontaneous combustion turns to flaming will be enhanced. The lower bulk density of spontaneous combustion, the more favorable for the spread of spontaneous combustion.

2) Compared with flaming, the spontaneous combustion is connected with chemical reaction, heat transfer, gas flow, diffusion and transformation of related substances and many other factors. Hence, the mechanism of spontaneous combustion is more complex. This paper has conducted the preliminary qualitative exploration and more in-depth studies especially for the critical condition when spontaneous combustion transforms into flaming should be carried out to reveal the mechanism of fibrous material and dust of grain spontaneous combustion.

\section{ACKNOWLEDGMENT}

The authors acknowledge the support provided by the International Science \& Technology Cooperation Program of China (2013DFG71760).

\section{REFERENCES}

[1] Editorial board of fire inspection handbook. "Fire inspection handbook," M. Shanghai, 1982.

[2] Y. Kameyama, F. S. Lai, H. Sayama and L. T. Fan, "The risk of dust explosions in grain processing and handling facilities," in Journal of Agricultural Engineering Research, vol 27, no 3, 1982, pp. 253-259.

[3] J. Gummer, G. A. Lunn, "Ignitions of explosive dust clouds by smoldering and flaming agglomerates," in Journal of Loss Prevention in the Process Industries, vol 16, no 1, 2003, pp. 27-32.

[4] P. Aldushin, A. Bayliss, B.J. Matkowsky, "On the mechanism of triggering the transition from smoldering to flaming," in Proceedings of the Combustion Institute, vol 31, no 2, 2007, pp. 2661-32. 2668.

[5] Carter R. J., "Smoldering combustion of wood fiber: cause and prevention,” in Journal of Fire and Flammability, vol 9, 1978, pp.119126.

[6] Moussa N. A., Toong T. Y., Garris C. A., "Mechanism of smoldering cellulosic materials," in 16th Symposium on Combustion, 1976, pp.1447- 1457.

[7] Leish S. O., "Smoldering combustion in horizontal dust layers," in The University of Michigan, Ann Arbor, 1983.

[8] Dosanjh S. S., Pagni P. J., "Forced cocurrent smoldering," in Combustion and Flame, vol 68, 1987, pp. 131-142.

[9] Fawaz K. Sweis, "The effect of admixed material on the flaming and smoldering combustion of dust layers” in Journal of Loss Prevention in the Process Industries, vol 17, no 6, 2004, pp.505-508.

[10] Xuguang Qi, Deming Wang, Xiaoxing Zhong, "Research on coal oxygen adsorption features at low-temoerature," in Coal Science and Technology, vol 36, no 3, 2008, pp. 58-61.

[11] Qiang Wu, Wensheng Chen, "The thermogravity analysis study on the spontaneous combusion of coal, " in Journal of Safety Science and Technology, vol 4, no 1, 2008, pp. 71-73.

[12] Fuqiang Yang, Chao $\mathrm{Wu}$, Guomin $\mathrm{Wu}$, "Prediction and forecast technology of spontaneous combustion of sulfide ore piles," in China Safety Science Journal, vol 17, no 5, 2007, pp. 89-95. 